\title{
Management of Emphysematous Pyelonephritis: About 8 Cases and Literature Review
}

EL Boukili El Makhoukhi Zayd*, ABDALLAH Hussein, Dergamoun Hamza, Hachem Al Sayegh, Benslimane Lounis, Nouini Yassine

“A” Department of Urology, Ibn Sina Teaching Hospital

DOI: $10.36348 /$ sjm.2020.v05i10.003 $\quad$ | Received: 07.09.2020 | Accepted: 24.09.2020 | Published: 11.10 .2020

*Corresponding Author: El Boukili El Makhoukhi Zayd

\section{Abstract}

Acute emphysematous pyelonephritis is a necrotizing and suppurative infection of the renal parenchyma and perirenal tissue with in situ production of gas of bacterial origin. This is a rare disease, occurring preferentially in diabetics and its mortality is hight. Our study aims to highlight the clinical and paraclinical characteristics as well as the particularity of therapeutic management of this pathology. We analyzed the medical files of patients treated for treated in the Department of Urology A; of the CHU IBN SINA Rabat between 2005 and 2020. For each medical file we specified clinical, paraclinical and therapeutic characteristics as well as the evolution after treatment. The treatment of those patients can typically be divided into medical management, medical management plus endoscopic or percutaneous drainage, and emergency nephrectomy. Nevertheless, given that there are very few guidelines or treatment algorithms, there is no consensus on the mana- gement of patients with emphysematous pyelonephritis.

Keywords: Pyelonephritis, urinary tract infection, diabetes, computed tomography.

Copyright () 2020 The Author(s): This is an open-access article distributed under the terms of the Creative Commons Attribution 4.0 International License (CC BY-NC 4.0) which permits unrestricted use, distribution, and reproduction in any medium for non-commercial use provided the original author and source are credited.

\section{INTRODUCTION}

Emphysematous pyelonephritis (EPN) is a necrotic infection of the kidney, characterized by the presence of gas inside the renal parenchyma, the execratory cavities or the perirenal spaces.

It is a severe albeit rare infection, that occurs mainly in immunocompromised subjects with unbalanced diabetes and it has a female predominance. It is a life threatening emergency.

Computed tomography is the gold standard for a positive diagnosis of gas presence. The management is still controversial. Between a nephroctomy and a purely medical treatment, there is a place for a more conservative treatment consisting of drainage, be it percutaneous or surgical, that can be proposed when there is no severity factor.

\section{RESULTS}

We did a retrospective study in our department of urology «Urologie A » in CHU Ibn-Sina Rabat, on a 15 years period between January $1^{\text {st }} 2005$ and January $1^{\text {st }} 2020$.

The study includes eight consecutive patients who were treated for an emphysematous pyelonephritis.
For each case, we have gathered the epidemiological, clinical, biological, radiology, therapeutic and evolutive data.

In our series, we have compiled 8 patients, 6 females $(75 \%)$ and 2 males $(25 \%)$. The median of age for our patients was 49, with extremes going from 27 to 72 years old.

The impairment of the left kidney happened in 5 of our patients, representing $62.5 \%$, while 3 patients had an impairment of the right kidney, representing $37.5 \%$. There wasn't any bilateral impairment in our study.

\section{Personnal history in our patients included}

- $\quad$ Type 2 diabetes in 5 patients

- Urolithiasis in 2 patients

- 1 case of Lupus

- 1 case of cholecystectomy

The principal indicative functional symptoms reported by our patients were low back pain and/ or renal colic with fever in 5 of our patients, symptoms of the lower urinary tract in 2 of ours patients and macroscopic hematuria in one patient. 
A work up including a CBC, CRP, fasting blood glucose, blood electrolytes, and renal function, and urinalysis and blood cultures was requested for all our patients.

Hyperleukocytosis over 11000 elements/mm3 was found in all our patients. CRP superior to $100 \mathrm{mg} / \mathrm{l}$ was found in $87.5 \%$ of cases.

All diabetic patients had unbalanced diabetes with hyperglycemia. The urinalysis was positive in all our patients with predominance for E.Coli in $62.5 \%$.

The blood cultures were negative in half our patients. Plain urinary tract showed gaseous clarities that projected onto the renal area in 2 patients and an image with calcic tonality projected onto the urinary tract in 2 others.

The ultrasound found an ureterohydronephrosis without obstruction in 2 patients and a hydronephrosis upstream of a left pyelic stone in another patient.

The diagnosis was confirmed with a uroscan. And based on the Huang \& TSENG classification, 3 patients were classified as stage $3 b$ (Figure 1), 2 patients presented with a 3a stage, 2other patients were classified as stage 2 (Figure 2) and only one was a stage 4.

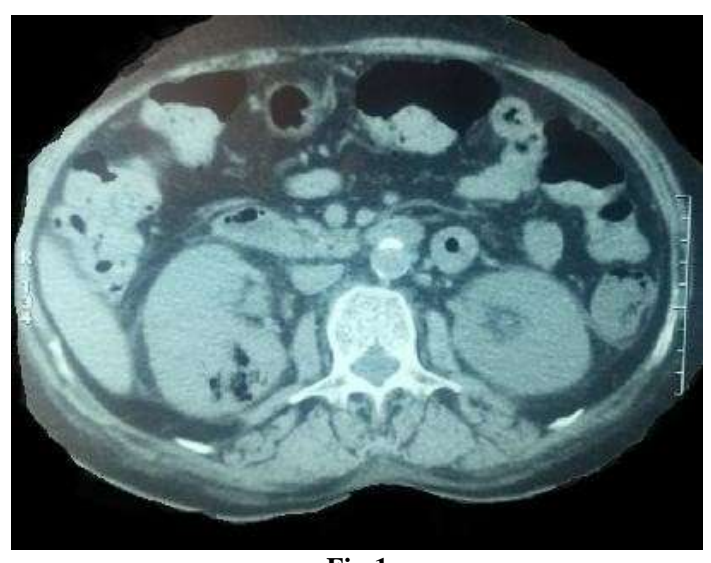

Fig-1

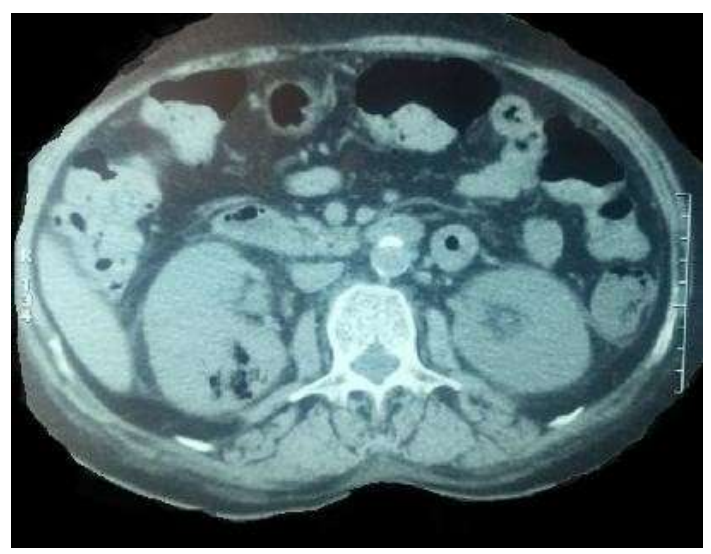

Fig-2
Furthermore, we found obstructive kidney and ureteral stones in 4 patients. All our patients benefited of hydroelectrolytic and acid-base management with insulin therapy for the diabetic patients; guided by the results of the work up.

A probabilistic bi antibiotic therapy using $3^{\text {rd }}$ generation cephalosporin and aminoglycoside was administrated to all our patients. The antibiotic therapy was readjusted after the results of the antibiogram were obtained. The duration of treatement was between 4 and 6 weeks.

Two of our patiens benefited from a percutaneous drainage of a perirenal collection. In the other patients, we carried out drainage of the urinary tract with a percutaneous nephrostomy in one patient and a double pigtail stent in 3 patients.

We didn't perform any nephrectomy in our patients. The clinical, biologial and radiological evolution was good with kidney conservation in all our patients.

The control uroscan showed a complete disappearance of gas and air bubbles in the urinary tract and the retro perirenal spaces.

\section{DISCUSSION}

Emphysematous pyelonephritis (EPN) is a severe and necrotizing form of acute bacterial pyelonephritis, resulting in the production of gas inside the renal parenchyma. It is a rare and serious disease encumbered with a mortality that goes from $7 \%$ to $75 \%$ depending on the series [1].

Kelly and MacCallum have described the first case of gaseous renal infection in 1989 and terms like "renal emphysema" and "pneumonephritis" were used to describe it [2]. The terme emphysematous pyelonephritis was introduced by Schultz and Klorfein in 1962 [3].

Its incidence is increasing due to a better understanding of the disease, of the diffusion of CT, or the increase of diabetes' incidence in Asia and industrialized countries [4]. Indeed, it interests in $90 \%$ of cases diabetic patients, more willingly the ones with unbalanced diabetes [5]. An obstruction to the flow of urine, extrinsic or intrinsic, is found in 20 to $40 \%$ of cases.

It affects primarily adults, occurs more frequently in women with a sex ratio of $1 / 1.8$ according to Michaeli et al. [7]. In our study, $75 \%$ of patients were women.

In almost all cases, the germs responsible are gram-negativ bacillus. E.Coli is found in $60 \%$ of the cases, Klebsiella Pneumoniae in $25 \%$ of the cases. In 
some cases, Pseudomonas or Proteus Mirabilis or Vulgaris are found $[8,9]$.

The clinical symptomatology is not specific. The usual presentation is that of an infectious syndrome with urinary symptoms [10]. The abdominal pain is often forefront and pneumaturia is exceptionally found [11].

Biological testing shows a nonspecific inflammatory syndrome. The cytobacteriological urinalysis and eventually blood cultures provide the diagnosis of a gram-negatif bacillus infection.

Radiography of a plain urinary tract reveals the renal emphysema in $85 \%$ of cases or a pneumoretroperitoneum.

The renal ultrasound is difficult to interpret. It could show areas of increased echogenicity with posterior fading and reverberation corresponding to gas bubbles, but it doesn't allow for a precise staging of the disease [13].

The computed tomography is the key and most decisive exam not only for a positive and aetiological diagnosis but also for the follow up of the disease. It allows for a precise localization of the gas in the renal parenchyma or the collection system or in the perinephritic space. Huang and Tseng established a radiological classification that has a prognostic value and that conditions the therapeutic choice [14].

Emphesymatous pyelonephritis is a therapeutic emergency. The treatment of patients affected with emphysematous pyelonephritis can be generally divided as follows:

- Medical management

- Endoscopic or percutaneous drainage

- Emergency nephrectomy

Three principal methods were adopted for treating EPN: exclusive medical treatment, medical treatment associated with percutaneous or surgical drainage, and radical treatment i.e. nephrectomy.

Resuscitation maneuvers, correction of acidobasic and electrolytic disturbances, control of glycemia and early IV administration of antibiotics are the basis of treatment in patients affected with emphysematous pyelonephritis.

The antibiotics must be actif against gramnegative bacillus, by parenteral route for a good bioavailability, in a synergistic association for a better efficiency. The initial probabilistic antibiotic therapy combines a third generation cephalosporin or imipenem to a fluoroquinolone or an aminoglycoside and would be adapted later accordingly to the bacteriological results and clinical efficiency [17].
The therapeutic choice depends on the clinical state of the patient, the radiological classification and the existence or not of risk factors namely: thrombopenia, acute renal failure, a state of shock, and impaired consciousness. Huang, in his series of 48 patients (the most important one in literature) has defined 4 big radiological stages of EPN, with indications that were adopted by the majority of authors in recent publications [14].

1) For localized EPN (stage 1 and 2), percutaneous drainage and/or obstacle lift combined with medical treatment would grant good results.

2) For extended EPN (stage 3 and4) with benign manifestations (less than 2 risk factors), percutaneous drainage combined to medical treatment would be the first line treatment.

3) For extended EPN with a fulminating evolution (two risk factors or more), nephrectomy provides the best results and should be rapidly performed.

Conservative treatments occupies more and more a bigger place thanks to the progress made in antibiotic therapy and resuscitation means, as well as in the field of medical imaging.

\section{REFERENCE}

1. Wan, Y. L., Lo, S. K., Bullard, M. J., Chang, P. L., \& Lee, T. Y. (1998). Predictors of outcome in emphysematous pyelonephritis. The Journal of urology, 159(2), 369-373.

2. Ubee, S. S., McGlynn, L., \& Fordham, M. (2011). Emphysematous international, 107(9), 1474-1478.

3. Abdul-Halim, H., Kehinde, E. O., Abdeen, S., Lashin, I., Al-Hunayan, A. A., \& Al-Awadi, K. A. (2005). Severe emphysematous pyelonephritis in diabetic patients. Urologia internationalis, 75(2), 123-128.

4. Grimaldi, A. (2003). Type 2 diabetes: The epidemy is in hand [Diabète de type 2: L'épidémie annoncée est en cours]. Rev. Prat, 53(10):1067-8

5. Michaeli, J., Mogle, P., Perlberg, S., Heiman, S., \& Caine, M. (1984). Emphysematous pyelonephritis. The Journal of urology, 131(2), 203-208.

6. Hudson, M. L. A., Weyman, P. J., van der Vliet, A. H., \& Catalona, W. J. (1986). Emphysematous pyelonephritis: successful management by percutaneous drainage. The Journal of urology, 136(4), 884-886.

7. Sharma, P. K., Sharma, R., Vijay, M. K., Tiwari, P., Goel, A., \& Kundu, A. K. (2013). Emphysematous pyelonephritis: Our experience with conservative management in 14 cases. Urology annals, 5(3), 157.

8. Angulo, J. C., Dehaini, A., Escribano, J., \& Sanchez-Chapado, M. (1997). Successful conservative management of emphysematous pyelonephritis, bilateral or in a solitary kidney. Scandinavian journal of urology and nephrology, 31(2), 193-197. 
9. Benchekroun, A., Ghadouane, M., Alami, M., Nouini, Y., \& Marzouk, M. (2000). Pyélonéphrite emphysémateuse sur rein lithiasique causée par un acinétobacter. Progrès en urologie (Paris), 10(1), 89-91.

10. Lowe, B. A., \& Poage, M. D. (1991). Bilateral emphysematous pyelonephritis. Urology, 37(3), 229-232.

11. Bahloul, A., Koubaa, A., Letaief, Y., Mhiri, M. N., \& Jemel, S. (1993). La pyélonéphrite emphysémateuse. A propos de 4 cas. Progrès en urologie (Paris), 3(5), 803-811.

12. Lim, C. S., Kim, W. B., Kim, Y. S., Ahn, C., Han, J. S., Kim, S., \& Lee, J. S. (2000). Bilateral emphysematous pyelonephritis with perirenal abscess cured by conservative therapy. Journal of nephrology, 13(2), 155-158.

13. Mongha, R., Punit, B., Ranjit, D. K., \& Anup, K. K. (2009). Emphysematous pyelonephritis-case report and evaluation of radiological features. Saudi Journal of Kidney Diseases and Transplantation, 20(5), 838.
14. Huang, J. J., \& Tseng, C. C. (2000). Emphysematous pyelonephritis: clinicoradiological classification, management, prognosis, and pathogenesis. Archives of Internal Medicine, 160(6), 797-805.

15. Aswathaman, K., Gopalakrishnan, G., Gnanaraj, L., Chacko, N. K., Kekre, N. S., \& Devasia, A. (2008). Emphysematous pyelonephritis: outcome of conservative management. Urology, 71(6), 1007-1009.

16. Olvera-Posada, D., Armengod-Fischer, G., Vázquez-Lavista, L. G., Maldonado-Ávila, M., Rosas-Nava, E., Manzanilla-García, H., ... \& Rodríguez-Covarrubias, F. (2014). Emphysematous pyelonephritis: multicenter clinical and therapeutic experience in Mexico. Urology, 83(6), 1280-1284.

17. Derouiche, A., Ouni, A., Agrebi, A., Slama, A., Slama, M. B., \& Chebil, M. (2008). La prise en charge des pyélonéphrites emphysémateuses. À propos de 21 cas. Progrès en urologie, 18(2), 102107. 